Trinity University

Digital Commons @ Trinity

Philosophy Faculty Research

Philosophy Department

8-2007

\title{
Worlds Are Colliding! Explaining the Fictional in Terms of the Real
}

Andrew Kania

Trinity University, akania@trinity.edu

Follow this and additional works at: https://digitalcommons.trinity.edu/phil_faculty

Part of the Philosophy Commons

\section{Repository Citation}

Kania, A. (2007). Worlds are colliding! Explaining the fictional in terms of the real. Philosophical Studies, 135(1), 65-71. doi:10.1007/s11098-007-9093-0

This Post-Print is brought to you for free and open access by the Philosophy Department at Digital Commons @ Trinity. It has been accepted for inclusion in Philosophy Faculty Research by an authorized administrator of Digital Commons@ Trinity. For more information, please contact jcostanz@trinity.edu. 


\section{Worlds are Colliding! Explaining the Fictional in Terms of the Real}

[Author's final manuscript; please cite only the published version:

Andrew Kania. "Worlds are Colliding! Explaining the Fictional in Terms of the Real"

Philosophical Studies 135 (2007): 65-71.]

GEORGE: You couldn't figure out the worlds theory for yourself? It's just common sense anybody knows ya gotta keep your worlds apart.... Worlds are colliding! ${ }^{1}$

In the 'Pool Guy' episode of Seinfeld, George is tormented by the infiltration of one of his social spheres - that he shares with his fiancée Susan - by people from another - that of his slacker friends, Jerry, Elaine, and Kramer. The delicate balance George has struggled to achieve with Susan threatens to be destroyed by this infiltration. In 'Both Sides of the Story', Gregory Currie examines a similar kind of delicate balance between the real world and fictional worlds, together with ways that balance can be upset. The question of what role the artist's actions play in the economy of our interaction with artworks is usually discussed with respect to the question of interpretation: What part, if any, do the artist's intentions play in determining the meaning of the work? Questions about how we understand fiction, on the other hand, have typically been answered with theories of what the audience does when confronted with a work of that kind. Currie shows us something of how these two aspects of fictions are bound up with one another. We are always aware that the fiction with which we are engaging is the product of actual intentional action, even when we are fully absorbed in it, trying to make sense of the fictional world on its own terms. 
The two kinds of explanation that Currie points out we must make use of in order to understand a fiction are internal and external explanations. An internal explanation is one in which both the explanandum and explanans are fictional. Thus, we explain Selma's saving all her money, in Lars von Trier's Dancer in the Dark (2000), by reference to the expense of the operation her son requires, while we understand that the savings and the operation, like Selma and her son themselves, are fictional. An external explanation is one in which a fictional explanandum is explained by something actual. Thus, we might explain the temporal and geographical location of Dancer in the Dark1964 Washington state - by pointing out that much of the emotional impact of the final scene depends on Selma's being executed by hanging, and that this was the sanctioned method of capital punishment in 1964 Washington. ${ }^{2}$ Thus we explain the fictional location in terms of the writer-director's desire for a certain effect.

It is worth pointing out, for the sake of completeness, that there are explanations in which the explanandum is actual and the explanans fictional - Charles is sweating because the slime is looking right at him. It sounds odd at first to suggest that something actual might be explained by something fictional, since the fictional does not exist. But, of course, the fictional does exist in some sense. There is no slime that is looking at Charles, but it is fictional that there is a slime looking at Charles. Currie ignores cases like these since he is concerned here only with various kinds of explanations of the fictional.

\section{Quibbles}

Currie's subtitle suggests that he is concerned primarily with narratives. But it seems to me that fiction is his target kind. One of his central examples - Hans Baldung Grien's 
woodcut The Holy Family (1511) - is a narrative work only in a pretty broad sense of 'narrative'. If paintings like this count as narratives, then it seems all fictions will. On the other hand, Currie's observations about explanations presumably do not apply to uncontroversial cases of non-fictional narrative. If we are reading an account of how the first explorers discovered the islands of New Zealand, there is no such thing as a 'silly question' in Walton's sense (Walton, 1990, pp. 174-83). It is always possible to sensibly ask how they navigated their vessels, what the weather patterns were like at the time, how they sustained themselves during the voyage, and so on, even if it is impossible for us to answer these questions. Yet all of these might be silly questions to ask about the voyage of the ship wrecked at the beginning of Twelfth Night. While it is appropriate to consider why the author has chosen to structure a non-fictional narrative in a certain way, it is not appropriate to appeal to the author's actions to explain the events within the narrative. Thus, I will be discussing Currie's arguments as they apply to fictions, rather than narratives.

I am also a little puzzled by Currie's interest in our tendency to be 'magical externalists'. Currie argues that there are two kinds of externalist explanation. One is actual, and explains the fictional by means of the actual: We ought to imagine that Selma has an eye condition because von Trier makes it clear that we should imagine this, by his use of cinematic conventions, having actors say and do certain things, and so on. The other, magical externalist, kind of explanation is apparently make-believe: We imagine that von Trier has magical powers which he uses to create a world that includes a woman called Selma who has an eye condition. I agree that we unreflectively, and often postreflectively, talk as if we believe that artists create worlds, populate them with real 
people, cause things to happen, and so on, as if artists were demigods. But, as Currie points out, none of us - the unreflective included - really believes this. How are we able to explain our verbal behavior, then? With some theory of fiction. Currie seems happy to appeal, like many, to Walton's make-believe theory of fiction, though he has elaborated his own theory elsewhere (Currie, 1990). But if our theory of fiction explains away our apparent allegiance to magical externalism, we have no need for two distinct kinds of externalist explanation - the actual and the make-believe. As a corollary, when we are being theoreticians I think it behooves us to 'speak with the learned', that is, use the terms of the theory that we think is correct. Thus I favor discussing externalist explanations in terms of actual artists making things fictional by playing a certain role in particular games of make-believe. I don't think this has any serious consequences for Currie's conclusions, I just think the whole picture would be more elegant without the magical externalism.

\section{Kinds of explanation and relations between them}

Before moving to a consideration of the various kinds of relation between internal and external explanations, it is worth pointing out that there are artistically relevant explanations of which both the explanandum and the explanans are external to the fictional world. We might call such explanations exterior. For instance, the large number of occurrences of the letter 'c' in the 'Ithaca' chapter of James Joyce's Ulysses (1922) is significant both statistically and artistically. John Gordon has convincingly argued that Joyce intentionally larded the chapter with this letter in order to add yet one more layer to the arcs of the chapter, "from the 'arc' subtended by the walkers at its beginning...to the 'flexed' posture adopted by the sleepers at its end..., from the celestial 'Northern 
Crown'...to 'the protruding part of the great toenail'..." (Gordon, 1994, p. 45). These arcs, recalling Odysseus's bow, "are emblems of homecoming, straight-shooting, hitting the target, satisfactory completion" (Gordon, 1994, p. 46). Clearly, the shapes of the constituent letters of 'Ithaca' are no more part of the fictional world of Ulysses than those of any (ordinary) novel. Nonetheless, the shape and number of tokens of the letter ' $c$ ' are relevant to a full appreciation of 'Ithaca' and its place within Ulysses as a whole.

What discrete succession of images did Stephen meanwhile perceive?

Reclined against the area railings he perceived through the transparent kitchen panes a man regulating a gasflame of $14 \mathrm{CP}$, a man lighting a candle of $1 \mathrm{CP}$, a man removing in turn each of his two boots, a man leaving the kitchen holding a candle.

(Joyce, 1922, p. 547)

Why is the candlepower of the Blooms' gasflame recorded in abbreviated form ("CP")? In part because it increases the percentage of 'c's in the chapter (and allows the curvature of the capital ' $\mathrm{P}$ ' to add to the effect). Thus we have an artistically relevant explanation of something external to the fictional world (how the power of the fictional gasflame is represented) in terms of something else actual (Joyce's desire to have a high proportion of 'c's and other curves in 'Ithaca'). Yet this explanation is part of a complete understanding of 'Ithaca', and hence Ulysses.

The addition of exterior explanations complicates Curries taxonomy of relations between internal and external explanations. In addition to these complications, I will suggest one or two ways in which the taxonomy might be improved, principally by the addition of a category of harmonious relations, and the removal of the categories of tension and collapse. 
Exclusion occurs when a request for an internal explanation of some feature of the fictional world would be a 'silly question' in the technical sense, such as the question of why all the diners in the 'Last Supper' are seated on one side of the table. Note that exclusion only occurs in one direction. External explanations are never excluded by internal ones, since there are no silly questions about the actual world; there is always some explanation in actual terms of why something is fictionally the case. However, both internal and external explanations may be excluded by exterior explanations. For instance, we may ask about the passage from 'Ithaca' quoted above why Stephen is reclined, rather than leaning, say, against the railings. This is surely a silly question, construed internally (if it even makes sense to construe it internally). Yet it seems plausible that there is no interesting external explanation of this, either (though one is on dangerous ground making such claims about Joyce). However, there is an exterior explanation available: Joyce slips one more 'c' into 'Ithaca' by describing Stephen as 'reclining' rather than 'leaning'. This the exterior explanation excludes the internal and external in this case.

With three possibilities now on the table, we can begin to see some of the complications of Currie's taxonomy. Consider another passage from 'Ithaca':

Had Bloom discussed similar subjects during nocturnal perambulations in the past?

In 1884 with Owen Goldberg and Cecil Turnbull at night on public thoroughfares between Longwood avenue and Leonard's corner and Leonard's corner and Synge street and Synge street and Bloomfield avenue. (Joyce, 1922, p. 545)

The question of why Turnbull's first name is Cecil is presumably a silly one if construed internally. (Of course, that this character has a name at all can be explained internally: 
People get names in the Dublin of Ulysses just as they do in the actual Dublin. But to ask, in the internal sense, why this character has the particular name 'Cecil' seems silly.) The same sort of exterior explanation of 'Cecil' is available as in the case of Stephen's reclining. 'Cecil' is forty percent ' $c$ ', and thus adds to this element of the chapter's symbolism. Yet, because 'Cecil', unlike 'reclined', is a name, this explanation can also be glossed as external. Why is it fictionally the case that one of the people Bloom has chatted with on his nighttime walks in the past has two 'c's in his name? Because Joyce wanted a high proportion of 'c's in 'Ithaca'. Here, the exterior and external explanations together exclude an internal one. The relationship between the exterior and external explanations in this example I would describe as one of harmony, to be explained below.

Dominance occurs when two kinds of explanation are available, but one is more salient than another. Any transparent plot device will serve as an example of the dominance of an external explanation over an internal one. Why does Desdemona drop her handkerchief? Well, people drop their handkerchiefs all the time in the actual world, and thus they do so in the fictional world, since Shakespeare has not indicated anything to the contrary. But clearly a more salient answer is that Shakespeare needs something that Iago can use to plant a seed of jealousy in Othello's breast. Thus, the latter explanation is more salient to our understanding of the play; it 'dominates' its internal competitor. The more obvious the external explanation is in cases like this, the closer one gets to a deus ex machina, as in Currie's example of the characters falling down a ravine in the Home Counties.

Dominance by an internal explanation is more difficult to describe, and this difficulty points to an important relation between kinds of explanation that Currie does 
not mention explicitly. All of Currie's terms for these relations have negative connotations: exclusion, dominance, tension, collapse. Yet internal and external explanations can often be harmonious. Why does Selma, in Dancer in the Dark, keep her savings in an old tin? Internally speaking, because she is naïve and, in short, this is what naïve people do. Externally speaking, it is fictional that Selma does this because von Trier wants it to be fictional that Selma is naïve. But both of these explanations are salient. We need the internal explanation to make sense of the fictional world, but we need the external explanation to make sense of the artwork. I think this harmony between internal and external explanations is probably the most common relationship between the two kinds, and thus deserves a prominent place in any taxonomy of such relations.

Nonetheless, dominance of the external by the internal is possible. Why is Selma represented as (literally) opaque as opposed to transparent? Simply because human beings in the fictional world are opaque for the same reasons people in the actual world are opaque. The external question here - Why did von Trier want his characters to be (literally) opaque? - is excluded from being technically silly, since there is always, in fact, an external explanation available for any fictional truth. (This is the same reason internal explanations can never exclude external ones, as mentioned above.) But neither the internal nor the external explanation of this fictional truth - like many others - is salient. This kind of dominance is relatively uninteresting, however, since the request for an external explanation in a case like this is as close to a silly question as you can get in the realm of the external. We might call such questions 'boring' rather than silly.

Tension occurs, it seems, when both an internal and an external explanation are available, and yet they are incompatible. Note that this is a slightly misleading 
simplification. To take Currie's example, if Pamela is a schemer, then we have an internal explanation of her detailed accounting of gifts, slights, and so on, in her letters. But there must also be an external explanation of this. Setting this explanation out might require us to take a stand on such contentious issues as the status of authorial intentions in the determination of the meaning of a work, since if Richardson did not intend Pamela to be a schemer, and one thinks his intentions are relevant to the determination of the content of the work, the external explanation of Pamela's scheming might have to be more complicated than if one were an anti-intentionalist. If, on the other hand, one of the somewhat baroque external explanations of the details in Pamela's letters is favored, the corresponding internal questions - how exactly letters get written in this fictional world, for instance - look pretty silly, and thus potential answers to them in terms of internal explanations are excluded by their external explanations. The tension here, though, is not between one external and one internal explanation, but two pairs of explanations - each consisting of one internal and one external explanation. Moreover, this tension is apparently epistemic. Once it is resolved, we are left with one pair of explanations, related harmoniously if Currie is right about which pair wins out, as I think he is. One more thing we can observe is that the dialectic that is required to settle which pair of explanations should be favored here is holistic. What is fictional in the work, how this is to be explained internally and externally, interpretations of the work, and so on, all have to be considered in settling the question at hand, even though each has consequences for the others. ${ }^{3}$ I revisit this issue below.

Collapse is supposedly a positive kind of tension. We have incompatible internal and external explanations, but we want to hold on to both of them, rather than choose 
between them. Currie's examples are 'metafictions' - works where the artist's role in determining what is fictional is foregrounded within the fictional world.

I am not convinced that these examples belong to a category distinct from those already considered. It is true that they require us to engage in make-believe with a distinct kind of content. We are to imagine that the world of the fiction is one in which something like Currie's 'magical externalism' is true - that objects and events in the world are under the control of a capricious demigod who shares many features with the author of the work. But though these kinds of imaginings make our heads spin, there does not seem to be any tension between the two sorts of explanations we might give of such fictional worlds. Internal explanations will appeal to The Author (a character as fictional as Rosencrantz and Guildenstern themselves); external explanations will appeal to the author (a person like Stoppard, who is as interested in the nature of fiction as Rosencrantz and Guildenstern are in their own nature). These explanations, rather than being in some anarchic relation best characterized as 'collapse', seem better characterized as being in a state of harmony, as glossed above. The theme that unifies them is a concern with the nature of fiction, but this is a matter of their content, and does not, in my view, affect their relation as explanations of a particular fictional world.

I have argued that Currie's central example of tension (the Pamela case) and his sub-category of tension (explanations in 'collapse') are in fact better characterized, at the end of the day, in terms of some other relation between their component internal and external explanations, be it one of exclusion, dominance, or harmony. Is tension between an internal and external explanation even possible, then, or is such tension always only apparent and epistemic, to be ultimately resolved into some other relation? I am chary of 
attempting to answer this question definitively here, but I will point to some of the reasons I think it is a difficult question to answer.

In order for there to be genuine tension between an internal and external explanation of some fictional truth, the explanations would have to be incompatible. Yet, as noted above, there must be some actual explanation for why something is fictionally the case. But then if the two were truly incompatible, we would have reason to favor the external explanation. This gives us reason to think cases of apparent tension will turn out to be cases of exclusion.

The case Currie discusses suggests that tension requires something weaker than incompatibility. The tension in the Pamela case is between Richardson's apparent (actual) intentions for the content of the novel, and what we might take from the book if we don't let those intentions determine its content. But this is not a tension between an external and internal explanation of the content of Pamela; it is a tension between the content of the work and what the author intended the content to be. Because intentions can fail, they are not always the simple external explanation of the fictional content of the work. Thus the tension in these cases is not between the internal and external explanations of that content. This is not to say that this tension is uninteresting; it is one point around which much of the debate about the meaning of fictional works revolves. But it does not seem to be a relation between the kinds of internal and external explanations of the fictional Currie is interested in in 'Both Sides of the Story'.

I will end by mentioning one more case that illustrates a few of the issues I have raised here - Thomas Pynchon's novella The Crying of Lot 49 (1965). A central mystery in that book is whether or not there is a massive conspiracy operative within the fictional 
world - the underground workings of The Tristero. There is much evidence of such a conspiracy, from a restroom graffito of a muted post horn, through the mail-system aberrations of W.A.S.T.E. and altered postage stamps and marks, to a mysterious Jacobean revenge tragedy. Yet all of this evidence is either circumstantial or ambiguous. Alternative (internal) explanations of it include coincidence, paranoia, or the playing of a gigantic practical joke. If we were in the shoes of the anti-heroine Oedipa Maas, perhaps agnosticism would be the appropriate epistemic response to this contestable evidence. But we are not in her shoes. We know that all this evidence has been carefully placed in the fiction, in such a way as to make it all circumstantial or ambiguous, by an intelligent being - Thomas Pynchon. ${ }^{4}$ This can induce some slippage between our internal and external explanations of the fictional world. It may seem that we have more evidence than Oedipa, that we know something she doesn't about the evidence she has access to, that it is not ambiguous or circumstantial but deliberately placed in her way. In the end I think this slippage is a confusion. There is no actual evidence, Pynchon only asks us to imagine a world where there is, and in which Oedipa is vainly seeking out its import. But Pynchon's inducement of this slippage in us coheres with some of his apparent concerns in writing the novel - the poor epistemic position we all seem to inhabit with respect to questions about our own place in the actual world, and its governance by a higher power, or lack thereof.

I would quarrel, then, with the details of Currie's taxonomy of relations between internal and external explanations of the features of fictions. On the one hand, there is an important kind of relation between the internal and external explanations of some fictional truths that Currie leaves out: that where both are salient, and yet in a relation of 
harmony with each other. On the other hand, I do not see that he has established that there is a genuine relation of tension between some pairs of internal and external explanations, and thus I question the usefulness of the category of collapse also. In addition, I think there is a different kind of explanation worth considering - the exterior explanation. Nonetheless, the chief value of Currie's paper remains - to point out to anyone with an interest in fictions the richness to be found in a consideration of the various relations between various kinds of explanations of features of those fictions.

Andrew Kania Trinity University 


\section{Notes}

${ }^{1}$ Seinfeld, 'The Pool Guy', season 7, episode 8.

${ }^{2}$ One might wonder, of course, about the need for realism in this detail, but I won't do so here.

${ }^{3}$ For a consideration of various 'levels' of a fiction and their relation to ontology and interpretation, see Goldman (2002).

${ }^{4}$ This is a simplification in terms of magical externalism, for, of course, it is not the evidence itself, but the details of Oedipa's discovery of it that are responsible for the ambiguity and circumstantiality. If Pynchon really were a demigod who had created a world, there would be no ambiguity (presuming certain logical limits on demigods). There would be either a conspiracy or not, depending on the details of the world he had created. 


\section{References}

Currie, G. (1990). The art of fiction. (New York: Cambridge University Press)

Currie, G. (200?). Both sides of the story: explaining the events in a narrative Philosophical Studies, ??, ???-???

Goldman, A. (2002). The sun also rises: Incompatible interpretations. (In M. Krausz (Ed.) Is there a single right interpretation? (pp. 9-25). University Park, PA: Pennsylvania State University Press)

Gordon, J. (1994). 'Ithaca' as the letter 'C'. James Joyce Quarterly, 32, 45-59

Joyce, J. (1922). Ulysses. The corrected text edited by H. W. Gabler with W. Steppe and C. Melchior. (New York: Penguin, 1986)

Walton, K. (1990). Mimesis as make-believe: On the foundations of the representational arts. (Cambridge, MA: Harvard University Press) 